\title{
AVALIAÇÃO DE CARACTERÍSTICAS FÍSICO- QUÍMICAS DAS ÁGUAS SUBTERRÂNEAS DO MUNICÍPIO DE PRANCHITA/PR
}

Edilaine Regina Pereira - edilainepereira@utfpr.edu.br

Universidade Tecnológica Federal do Paraná - Campus Londrina

Adriana Zemiani - adrianazemiani@utfpr.edu.br

Universidade Tecnológica Federal do Paraná - Campus Londrina

Fellipe Jhordã Ladeia Janz - fellipejanz@ hotmail.com

Universidade Tecnológica Federal do Paraná - Campus Londrina

Dandley Vizibelli - dandley.22@gmail.com

Universidade Tecnológica Federal do Paraná - Campus Londrina

Thaís Ribeiro - thaisribeiro@aluno.utfpr.edu.br

Universidade Tecnológica Federal do Paraná - Campus Londrina 


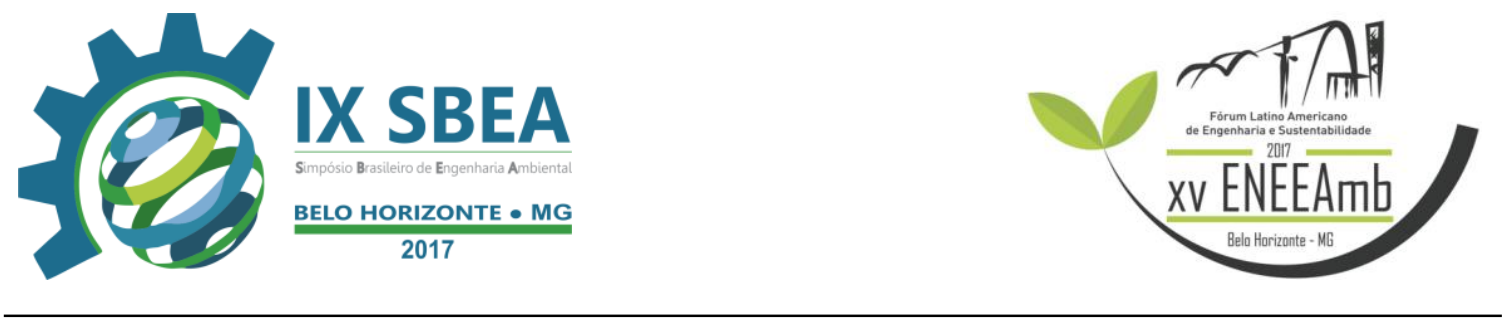

\section{RESUMO}

A água é um bem natural e sua fonte é escassa, sem água de boa qualidade a vida na terra fica comprometida. Diante disso, se faz necessário estudos para monitoramento da qualidade da água. A água subterrânea é utilizada em diversos lugares, principalmente cidades de menor porte onde ainda se encontra muitos poços nas residências. Poços perfurados sem um estudo técnico e sem um projeto adequado podem estar mais vulneráveis a contaminação. A contaminação da água subterrânea está associada a descartes inadequados de resíduos e efluentes bem como as intensas atividades agrícolas. O munícipio de Pranchita, localizado no sudoeste do Paraná possui uma atividade agrícola muito intensa, e o uso de água subterrâneas extraídas de poços na área urbana da cidade é muito comum. Objetivou-se com este estudo realizar análise de alguns parâmetros físicos e químicos $(\mathrm{pH}$, condutividade elétrica, turbidez, sólidos totais dissolvidos e nitrato) da água subterrânea de três poços do município de Pranchita a fim de buscar se essas águas estão tendo sua qualidade comprometida e se tal comprometimento tem relação com o uso de fertilizantes e pesticidas utilizados nas áreas agrícolas do entorno da cidade. Observou-se que apenas um poço (P3) apresentou um valor fora dos estabelecidos pela legislação e somente para o parâmetro turbidez, os demais resultados tanto para o poço P3 quando para os poços P1 e P2 estão dentro dos valores máximos permitidos pela legislação exceto para $\mathrm{pH}$ onde obtiveram um valor um pouco abaixo do recomendado ( $\mathrm{P} 1-\mathrm{pH} 5,25$ e $\mathrm{P} 2-\mathrm{pH} 5,24)$.

Palavras- Chave: Água Subterrânea, qualidade da água, poços, contaminação, áreas agrícolas.

\section{INTRODUÇÃO/OBJETIVO}

A muito tempo tem-se uma preocupação com a qualidade das águas tanto superficiais quanto as subterrâneas. Sabe-se que a água é um bem natural e escasso e que a sua preservação deve ser prioridade, para o bem das gerações atuais e futuras.

A captação de águas subterrâneas é realizada a partir de perfurações no solos até que se atinja a coluna d'água no subsolos, o lençol freático. Antigamente não se tinha água encanada e mesmo em áreas urbanas era normal que cada família tivesse um poço 


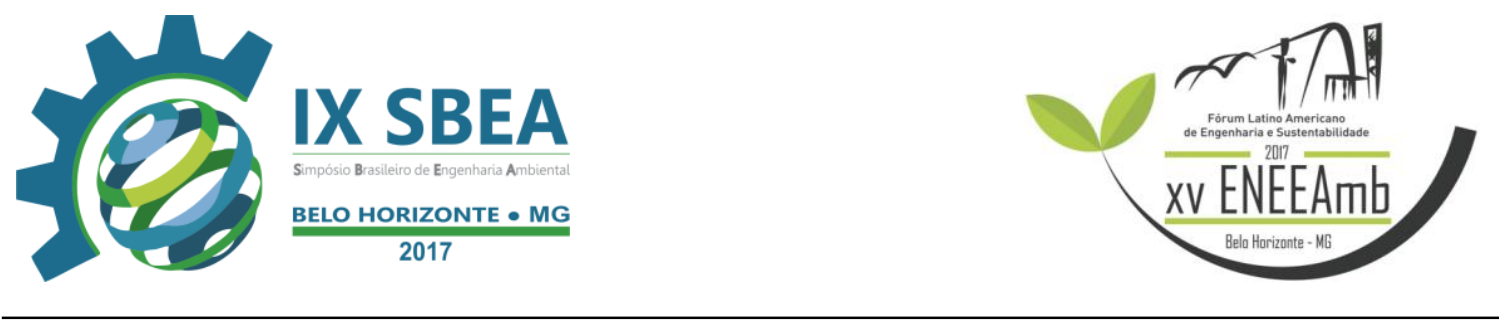

perfurado em sua casa, para uso da água para consumo. Ainda hoje, mesmo com água encanada muitas famílias utilizam dos poços para consumo, principalmente em municípios de menor porte.

Os riscos de contaminação que envolvem o uso das águas subterrâneas são decorrentes da má escolha do local para implantação do poço, ou de perfurações inadequadas, sem embasamento técnico, falta de cuidados com as medidas sanitárias dos poços, ou contaminação difusa sobre os mananciais, ou nas áreas de recarga (PERCEBON et al., 2009).

O uso intensivo dos recursos naturais subterrâneos e atividades agrícolas, associado à elevada produção de resíduos na sociedade, frequentemente causa ameaça à qualidade das águas subterrâneas. A degradação da qualidade das águas subterrâneas podem ocorrer em grandes áreas a partir de fontes difusas como percolação profunda de áreas intensamente cultivadas (WADE, 1998).

Embora as áreas agrícolas sejam consideradas como fontes difusas de contaminação ambiental por agrotóxicos, podem representar riscos para o meio ambiente, mais especificamente quanto à contaminação das águas superficiais e subterrâneas (FILIZOLA et al., 2005). O uso de agroquímicos nas lavouras, apesar de serem considerados relevantes insumos na agricultura mecanizada, além da problemática relacionada aos danos à saúde humana, pode gerar danos ao ambiente (OLIVEIRA \& VILLAR, 2014).

A Resolução CONAMA N 396 de 03 de Abril de 2008 dispõe sobre a classificação e diretrizes ambientais para o enquadramento das águas subterrâneas e dá outras providências. Essa Resolução apresenta lista de parâmetros com maior probabilidade de ocorrência em águas subterrâneas, seus respectivos Valores Máximos Permitidos (VMP) para cada um dos usos considerados como preponderantes e os limites de quantificação praticáveis (LQP), considerados como aceitáveis para aplicação desta Resolução.

O município de Pranchita está localizado no sudoeste do Estado do Paraná. A região Sudoeste do Paraná, bem como o próprio município citado é conhecida por sua forte atividade na agricultura. Com isso litros de fertilizantes e pesticidas são lançados ao solo durante o ano todo e em todas as safras cultivadas. A área urbana do município está 


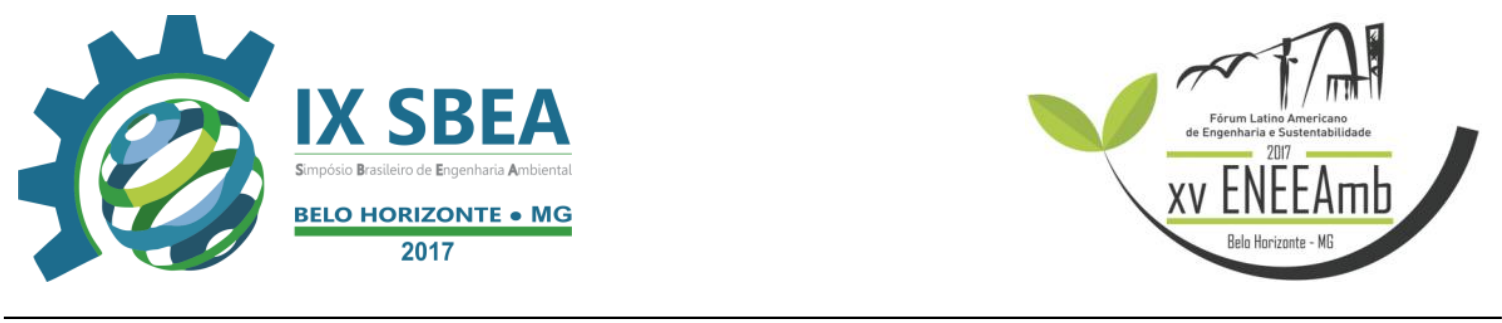

localizada em uma parte com altitude mais baixa e em seu entorno estão localizadas as áreas agrícolas, em uma área mais elevada (com maior altitude).

Levando em consideração que com grandes descargas da água da chuva todo o tipo de produto, químico ou biológico, aplicado nas culturas pode ser lixiviado podendo atingir o lençol freático, há uma preocupação em saber as condições em que esta água se encontra e se a mesma está recebendo alguma carga proveniente da atividade agrícola na região.

Diante disso, este trabalho tem por objetivo realizar um estudo preliminar de alguns parâmetros físicos e químicos da água de três poços do município de Pranchita e compará-los com a resolução CONAMA 369/08.

\section{METODOLOGIA}

O local de coleta foi o município de Pranchita, localizado no extremo sudoeste do Paraná. O município ocupa uma área territorial de 246 quilômetros quadrados, a uma altitude de 460 metros acima do nível do mar, longitude de $53^{\circ} 45^{\prime} 00^{\prime \prime}$ ' O e latitude de $26^{\circ} 00^{\prime} 00^{\prime}$ 'S. O clima é subtropical úmido mesotérmico, com temperatura mínima, de $11^{\circ} \mathrm{C}$ e máxima de $23^{\circ} \mathrm{C}$, sem estação seca definitiva, correspondendo ao tipo climático CFA segundo a classificação de Koppen. A precipitação pluviométrica do município é bem distribuída durante todos os meses, alcançando um índice de 1.800 a 2.000 milímetros anuais.

As amostras de água foram coletadas no mês de março, de três poços distribuídos no município, a Figura 1 apresenta os locais de coleta e a sua distribuição dentro da geolocalização do município. 



Figura 1. Localização do município de Pranchita e os pontos de coleta da água dos poços. Fonte: Google Earth, 2017.

As coletas das amostras de água foram realizadas no verão de 2017. As análises foram realizadas nos laboratórios de Saneamento da UTFPR - Londrina. A metodologia de coleta e preservação das amostras seguiu as orientações descritas por APHA (2012). As análises realizadas foram as de condutividade elétrica, $\mathrm{pH}$, nitrato, turbidez e sólidos totais.

As características de cada poço estão apresentadas no tabela 1.

Tabela 1. Característica dos poços amostrados.

\begin{tabular}{|c|c|l|}
\hline Amostra & $\begin{array}{c}\text { Profundidade } \\
\text { (m) }\end{array}$ & \multicolumn{1}{|c|}{ Características } \\
\hline P 1 & 12 & $\begin{array}{l}\text { Poço raso, fechado com construção de concreto, } \\
\text { com pouca vegetação no entorno, localizado } \\
\text { mais ao centro-norte do município. Utilizado } \\
\text { para consumo humano. }\end{array}$ \\
\hline P 2 & $\begin{array}{l}\text { Poço raso, fechado com construção de concreto, } \\
\text { com bastante vegetação no entorno, localização } \\
\text { mais próxima a rodovia e área agrícola. } \\
\text { Utilizado para consumo humano e } \\
\text { dessedentação de animais }\end{array}$ \\
\hline P 3 & $\begin{array}{l}\text { Poço raso, com construção de concreto, sem } \\
\text { vegetação no entorno, localizado mais ao } \\
\text { centro- sul do município. Utilizado apenas para } \\
\text { irrigação e lavagem de calçadas. }\end{array}$ \\
\hline
\end{tabular}




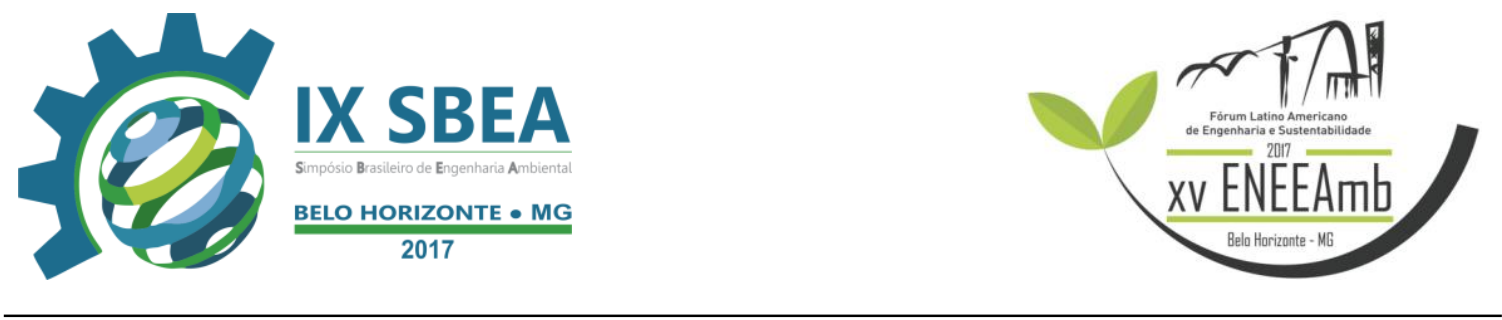

\section{RESULTADOS E DISCUSSÃO}

Para os parâmetros físicos foram analisados $\mathrm{pH}$, turbidez, cor e sólidos totais dissolvidos os quais estão expressos na Figura 2.
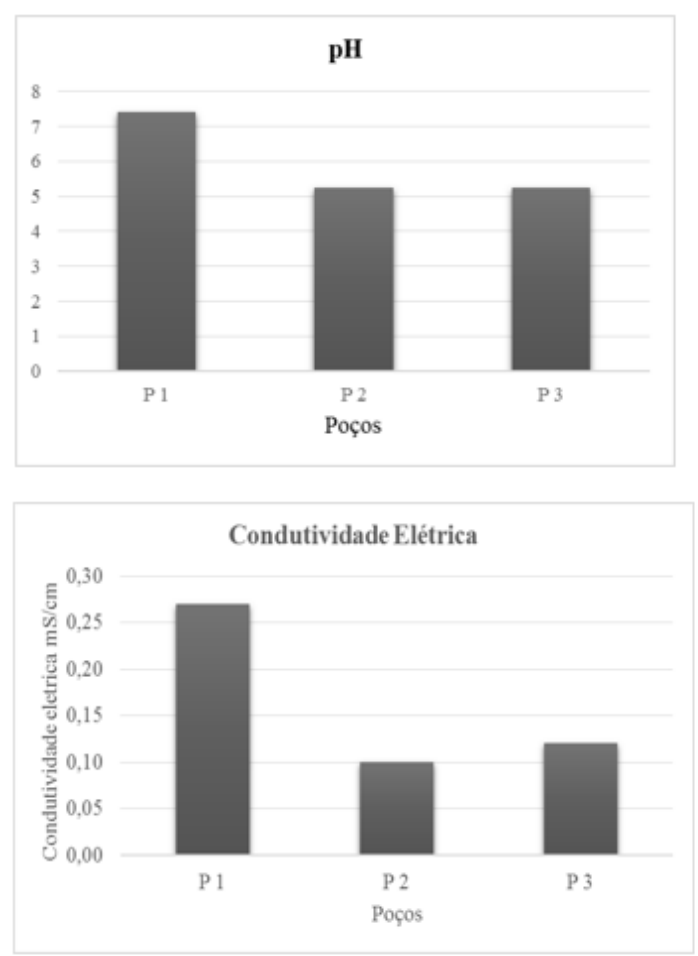
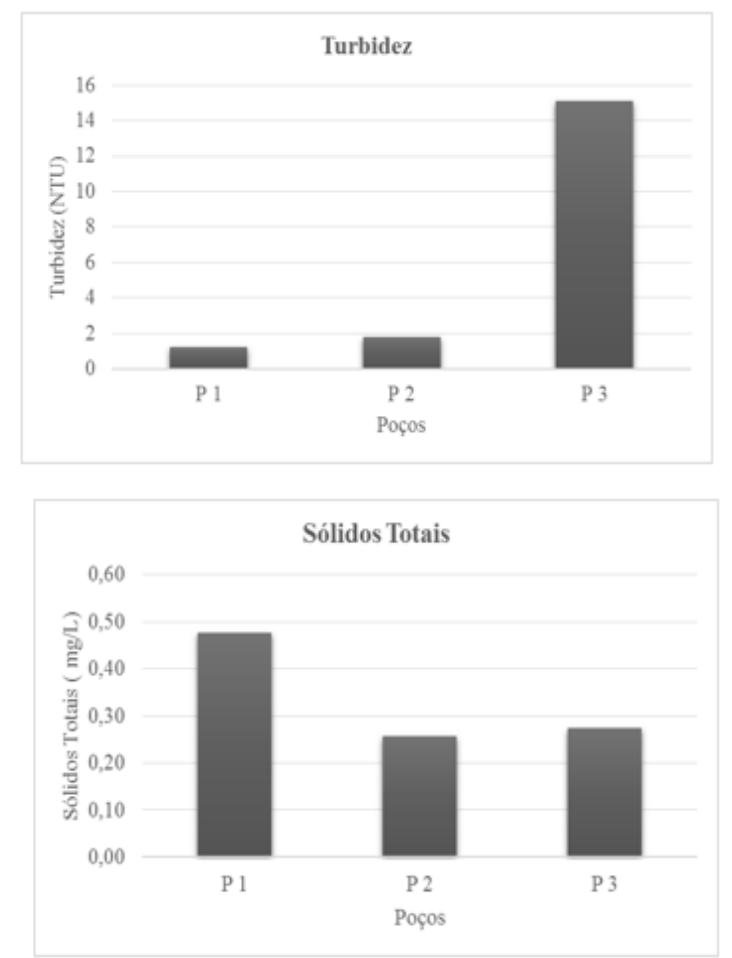

Figura 2. Resultados para leitura de pH, turbidez, condutividade elétrica e análise de Sólidos totais na água dos poços. Fonte. Próprios autores.

Todos os poços amostrados apresentaram valores de condutividade elétrica inferior a $100 \mathrm{mScm}^{-1}$, refletindo o ambiente intemperizado, característico da baixa profundidade dos poços amostrados (12, 6 e 12 metros) todos os poços encontram-se dentro dos limites desejáveis para o consumo humano $\left(<0,5 \mathrm{mS} \mathrm{cm}^{-1}\right)$ neste parâmetro.

Em relação à turbidez, o limite máximo para água potável deve ser de 5 UNT, observando-se que os poços P1 e P2 estão em conformidade com os permitidos estando o poço $\mathrm{P} 3$ com valor bem acima do estabelecido, no entanto o poço $\mathrm{P} 3$, como citado, não é utilizado para fins de consumo humano, apenas para irrigação e lavagem de calçadas.

O conteúdo máximo de sólidos totais (ST) nas amostras foi de $0,48 \mathrm{mg} \mathrm{L}^{-1}$ para o poço P1, seguido do poço P2 e P3 que obtiveram valores muito próximos, sendo de 0,26 e 0,27 respectivamente. 


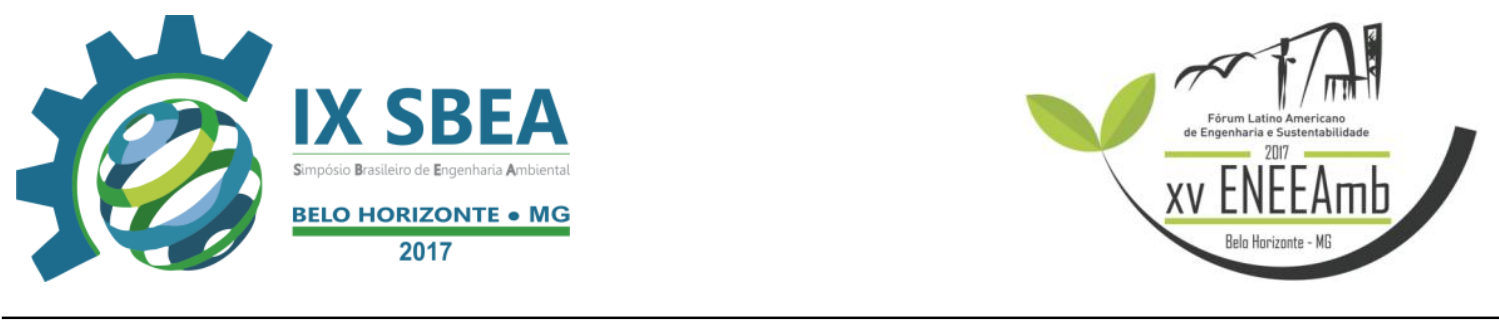

Além dos parâmetros mencionados acima, foi analisado também a concentração de nitrato nas amostras dos três poços. O nitrato é proveniente, em sua maior parte, do uso de fertilizantes nitrogenados. É um contaminante que pode provocar diversos agravantes na saúde dos seres humanos, principalmente de crianças, e animais. A Figura 3 apresenta as concentrações de nitrato para os poços analisados.

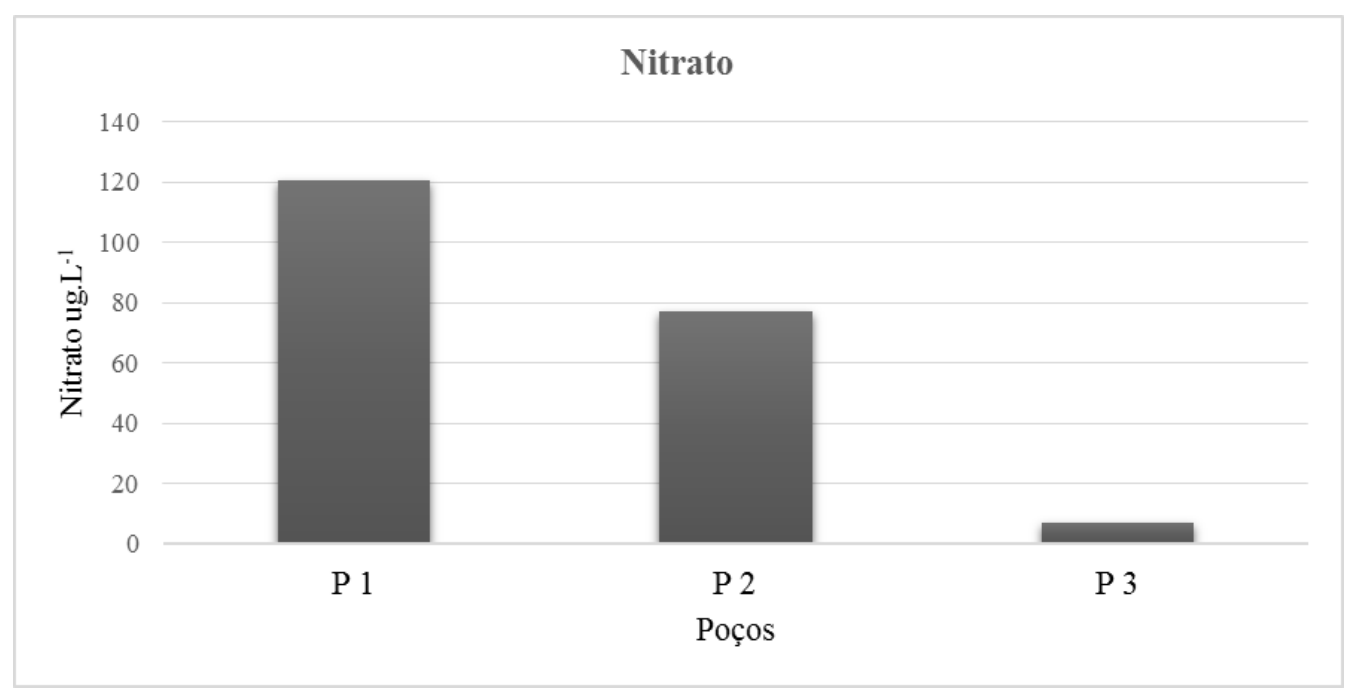

Figura 3. Concentração do nitrato $\left(\mathrm{mg} \cdot \mathrm{L}^{-1}\right)$ nos poços

A concentração de nitrato variou para cada poço, sendo que o poço P1 foi o que apresentou a maior concentração de nitrato $\left(0,12 \mathrm{mg} \mathrm{L}^{-1}\right)$, seguido do poço $\mathrm{P} 2$ apresentando uma concentração de $0,077 \mathrm{mg} \mathrm{L}^{-1}$ de nitrato e o poço P3 com o menor valor, apresentando uma concentração de nitrato de $0,007 \mathrm{mg} \mathrm{L}^{-1}$. Todos os valores encontrados encontram-se muito abaixo dos estabelecidos como máximo permitido pela resolução CONAMA 496/08, de 10,0 mg L ${ }^{-1}$.

Leite et., al. (2014) avaliaram alguns parâmetros de qualidade de 12 poços na região de Santa Catarina e um dos parâmetros analisado foi a concentração de nitrato na água. Eles encontraram valores acima de $5 \mathrm{mg} \mathrm{L}^{-1}$ de nitrato para 3 poços e apenas um poço obteve valores parecidos $\left(0,2 \mathrm{mg} \mathrm{L}^{-1}\right)$ com o encontrado nos poços do município de Pranchita. O nitrato é a principal fração de nitrogênio inorgânico dissolvido presente nas águas (BERNER \& BERNER, 1995). Altas concentrações podem estar associadas a contaminação de origem antrópica, como efluentes agrícolas ou domésticos (MANOEL FILHO, 2000). 


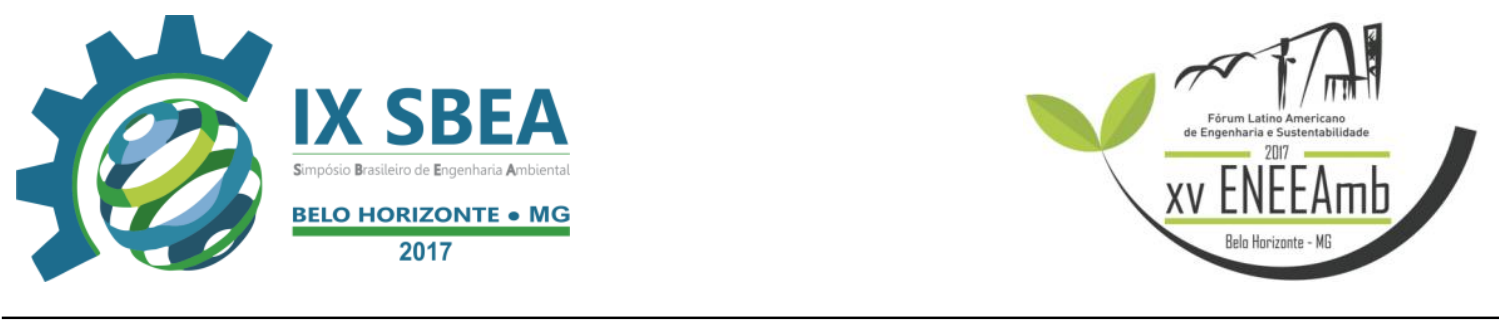

\section{CONCLUSÕES/RECOMENDAÇÕES}

Os resultados obtidos na análise preliminar evidenciam que as amostras de águas subterrâneas dos poços P1 e P2 encontram-se em conformidade com a legislação, atendendo às normas de potabilidade. $\mathrm{O}$ poço $\mathrm{P} 3$ não se enquadra na potabilidade para os parâmetros analisados por apresentar uma turbidez acida da permitida na legislação.

O resultado obtido em todos os parâmetros, inclusive o Nitrato não demonstraram que as água estão recebendo alguma influência da área agrícola, no entanto para tal confirmação deve-se realizar um estudo mais detalhado de mais parâmetros incluindo análises químicas de substâncias orgânicas e inorgânicas presentes no pesticidas e fertilizantes em geral. Ademais, os resultados contribuem para a criação de um banco de dados que permitirá avaliar o estado das águas subterrâneas na região.

Sugere-se com a execução do presente estudo que sejam realizadas coletas sazonalmente em diferentes períodos do ano para levar em consideração a precipitação local e as épocas em que se tenham a maior intensidade de aplicação dos produtos químicos nas lavouras do entorno da cidade.

\section{REFERÊNCIAS BIBLIOGRÁFICAS}

APHA - American Public Health Association. Standard methods for the examination of water and wastewater. $22^{\circ}$ Ed. Washington: American Public Health Association, 2012 .

BERNER, E.K., BERNER, R.A. Global Environment: Water, Air, and Geochemical Cycles. $1^{\text {a }}$ Ed. Englewood Cliffs: Prentice Hall, 1995.

EMBRAPA. Mapa Simplificado de Solos do Estado do Paraná. Curitiba: Embrapa / UFPR - CNPS, 2012.

FILIZOLA, H. F.; FERRACINI, V. L.; ABAKERLI, R. B.; GOMES, M. A. F. Monitoramento de agrotóxicos e qualidade das águas em área de agricultura irrigada. $\mathrm{R}$. bras. Agrociência, Pelotas, v.11, n. 2, p. 245-250, abr-jun, 2005.

MANOEL FILHO, J. Contaminação das águas subterrâneas. Cap. 6. In: Feitosa, F.A.C., Hidrogeologia: Conceitos e Aplicações. $2^{\text {a }}$ ed. Fortaleza: CPRM/REFO, LABHIDUFPE, 2000. 


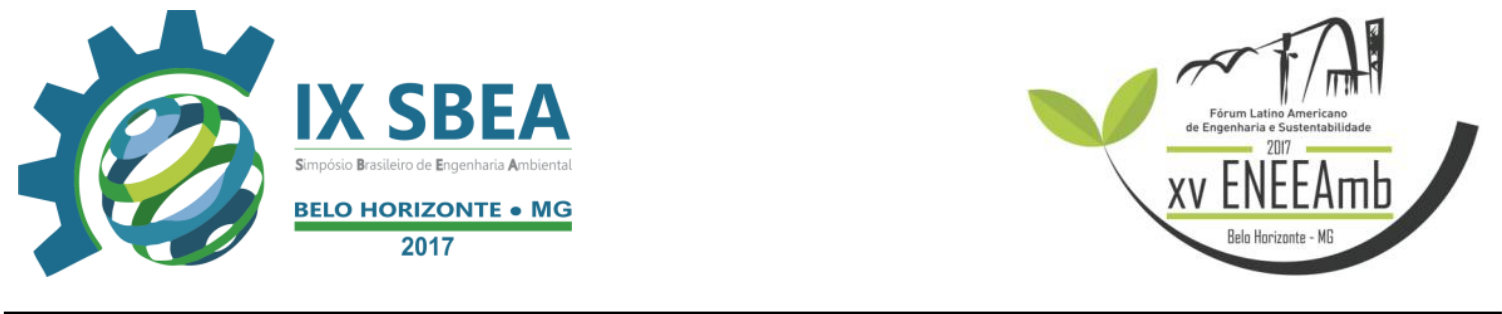

OLIVEIRA, L. T. \& VILLAR, P. C. Análise de Agrotóxicos na Região Oeste da Bahia e breve reflexão sobre a mobilidade de resíduos. Anais - XVIII Congresso Brasileiro de Águas Subterrâneas, 2014.

PERCEBON, C. M. \& BITTENCOURT, A. V. L. 2009. Considerações sobre as características de qualidade das águas subterrâneas de Blumenau - SC em relação à resolução CONAMA 396. Águas Subterrâneas, v.23, n.01, p.69-84.

RESOLUÇÃO CONAMA no 396, de 3 de abril de 2008. Dispõe sobre a classificação e diretrizes ambientais para o enquadramento das águas subterrâneas e dá outras providências Publicada no DOU no 66, de 7 de abril de 2008, Seção 1, páginas 64-68.

WADE, H.F. The impact of pesticide use on groundwater in North Carolina. Journal of Environmental Quality, Madison, v. 27, n. 5, p. 439-444, 1998. 